\title{
Shock Waves from lons Damage DNA
}

\section{Simulations show that the mechanical force of shock waves propagating through cells may be a key component of ion radiation damage to DNA.}

\author{
By Erika K. Carlson
}

W

hen astronauts go to space, ions bombard their tissues, creating free electrons and free radicals that can damage DNA. Experiments have hinted that shock waves generated when ions impact cells may also contribute to DNA damage. Now, Andrey Solov'yov of the MBN Research Center, Germany, and colleagues have developed a detailed theoretical description of how ion-induced shock waves impact and interact with DNA and have shown that it is likely a key component of DNA damage [1].

Researchers had previously proposed that when an ion strikes a cell, it triggers a shock wave in the cell's cytoplasm that propagates through the cell, breaking strands of DNA along the way. Solov'yov and colleagues fleshed out the idea and ran a series of molecular dynamics simulations of ion-triggered shock waves in water that containined DNA molecules, taking into account the production of free electrons and radicals as well. They compared their simulated results to previously published experimental data and found that, in many cases, the

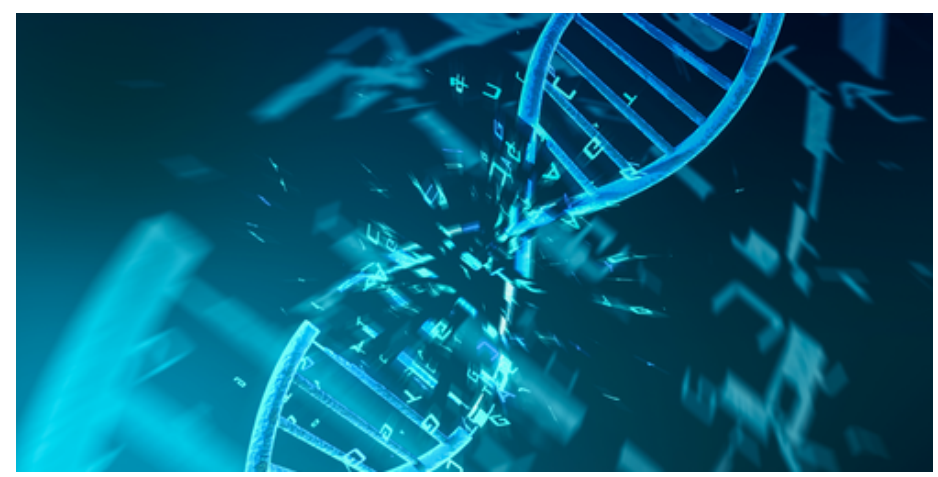

Credit: lucadp/stock.adobe.com simulations only matched the experiments when the shock-wave mechanism was included. The finding suggests that shock waves likely cause DNA damage.

The simulations also provide insight into the kind of damage ion radiation inflicts on DNA. The team found that shock-wave damage was, in some regimes, the dominant source of "complex" DNA damage, where multiple breaks occur along a short section of a DNA strand, with at least one of those breaks cracking both strands. Complex damage can be lethal for a cell. The team says that their findings my improve the risk calculations of space travel and the outcomes of cancer therapies.

Erika K. Carlson is a Corresponding Editor for Physics based in New York City.

\section{REFERENCES}

1. I. Friis et al., "Lethal DNA damage caused by ion-induced shock waves in cells," Phys. Rev. E 104, 054408 (2021). 